\title{
Integrating Circular Economy Strategies with Low-Carbon Scenarios: Lithium Use in Electric Vehicles
}

\section{$\operatorname{AUTHOR}(\mathrm{S})$ :}

Watari, Takuma; Nansai, Keisuke; Nakajima, Kenichi; McLellan, Benjamin C.; Dominish, Elsa; Giurco, Damien

\section{CITATION:}

Watari, Takuma ... [et al]. Integrating Circular Economy Strategies with Low-Carbon Scenarios: Lithium Use in Electric Vehicles. Environmental Science \& Technology 2019, 53(20): 11657-11665

\section{ISSUE DATE:}

2019-10-15

URL:

http://hdl.handle.net/2433/259703

\section{RIGHT:}

This document is the Accepted Manuscript version of a Published Work that appeared in final form in 'Environmental. Science \& Technology', copyright (c) American Chemical Society after peer review and technical editing by the publisher. To access the final edited and published work see https://doi.org/10.1021/acs.est.9b02872; The full-text file will be made open to the public on 2 October 2020 in accordance with publisher's 'Terms and Conditions for Self-Archiving'; の論文は出版社版でありません。引用の際には出版社版をご確認ご利用ください。; This is not the published version. 


\title{
1 Integrating Circular Economy Strategies with Low-
} 2 Carbon Scenarios: Lithium Use in Electric Vehicles \\ Takuma Watari ${ }^{1,2 *}$, Keisuke Nansai ${ }^{1,3}$, Kenichi Nakajima ${ }^{1}$, Benjamin C. McLellan ${ }^{4}$, Elsa \\ Dominish ${ }^{5}$, Damien Giurco ${ }^{5}$ \\ 1 Center for Material Cycles and Waste Management Research, National Institute for Environmental \\ Studies, 16-2 Onogawa, Tsukuba, Ibaraki 305-8506, Japan \\ 2 Graduate School of Frontier Sciences, The University of Tokyo, 5-1-5 Kashiwanoha, Kashiwa, Chiba 277- \\ 8563, Japan \\ 3 ISA, School of Physics, Faculty of Science, The University of Sydney, Camperdown, NSW 2006, Australia \\ 4 Graduate School of Energy Science, Kyoto University, Yoshida Honmachi, Sakyo-ku, Kyoto 606-8501, \\ Japan \\ 5 Institute for Sustainable Futures, University of Technology Sydney, Ultimo, NSW 2007, Australia \\ * Correspondence: watari.takuma@nies.go.jp; Tel.: +81-90-1683-1475
}

Abstract: Electrification of the transport sector will support its decarbonization, yet significantly change material requirements. This calls for an integrated modeling approach internalizing metal demand-supply dynamics in low-carbon scenarios to support the Paris agreement on climate change and sustainable material circulation. Here we develop a step towards the integrated simulation of energy-materials scenarios by unifying a stock-flow dynamics model for low-carbon scenarios using linear programming. The modeling framework incorporates lithium supply from both mines and end-of-life (EoL) recycling for projected use in Electric Vehicles on a global basis. The results show that supply constraints, which could become apparent from around 2030 in the case of current recycling rates $(<1 \%)$, would impede the deployment of Battery Electric Vehicles (BEVs), leading to the generation of an additional $300 \mathrm{Mt}-\mathrm{CO}_{2}$ of emissions for vehicle operation in 2050. Another important finding is that increasing the recycling rate to $80 \%$ could substantially relieve restrictions on the introduction of BEVs without requiring primary supply from natural deposits far beyond historical rates of expansion. While EoL recycling is important from a long-term perspective, an EoL-oriented strategy has little effect on the short/medium-term (such as to 2030) lithium demand-supply balance because of exponential demand growth and long living batteries. Importantly, findings in this study emphasize the necessity of tackling climate change and resource circulation in an integrated manner.

Keywords: Circular economy; Lithium-ion battery; Electric vehicle; Material flow analysis; Paris agreement; Recycle

\section{Introduction}

National commitments vis-à-vis the Paris agreement on climate change ${ }^{1}$ call for a move away from fossil fuels towards a large-scale energy transition accompanied by mass deployment of lowcarbon technologies including solar PV and electric vehicles (EVs) ${ }^{2,3}$. Such radical changes, however, could substantially affect existing metal resource cycles because these new technologies differ markedly from conventional technologies in terms of material composition, fuel consumption for operation and waste management ${ }^{4}$. This perspective leads to further concerns of resource constraints and adverse environmental implications associated with mining activities ${ }^{5}$ and calls for system design based on life-cycle thinking, taking into account the entire supply chain from resource mining through to end-of-life (EoL) management. Life Cycle Assessment (LCA) is a tool for achieving this, and has been applied in various contexts including renewable energy technologies ${ }^{6-8}$ and EVs 9,10 . These attempts, however, have largely ignored dynamic factors such as the electricity technology mix and the primary and secondary supply balance of metals, resulting in a 'snapshot' at a certain point in time. These snapshot analyses do not allow for adequate evaluation of new policies and technology 
implementation from a long-term perspective, which is pivotal in the context of environmental problems including climate change mitigation.

Reflecting the importance of overcoming this shortcoming, attempts have been made to undertake LCA with consideration of future technologies and policy evaluation, so-called prospective-LCA ${ }^{11,12}$. Prospective-LCA can examine future potential environmental impacts based on alternative scenarios by combining dynamic factors such as the electricity technology mix with inventory data ${ }^{13-15}$. Some studies, furthermore, attempt to assess the effects on metal resources demand by connecting data on the metal contents of each technology to energy scenario outputs from Integrated Assessment Models (IAMs) ${ }^{16-18}$. Although these studies evaluate the implications of dynamic systemic changes on metal demand and environmental impacts, the 'material cycles', which involve recovery from EoL products, have tended to be underemphasized. Indeed, no modeling study has hitherto incorporated the implications of circular economy strategies ${ }^{19}$ such as reuse and recycling on energy transitions and the accompanying environmental impacts. The norm has been to conduct one-way analyses that principally assess the impacts of low-carbon transitions on metal resource demand, meaning that the implications of resource supply constraints and circulation improvements on low-carbon transitions have not been adequately addressed. As pointed out in previous studies ${ }^{20,21}$, the nexus between energy and resources is critically important in the context of the Sustainable Development Goals (SDGs) 22, thus the development of a modeling framework that comprehensively incorporates the linkage is critical.

Dynamic-Material Flow Analysis (D-MFA), observing long-term material cycle dynamics with respect to mass balance, could potentially fill this gap ${ }^{23-26}$. By using this method, various bulk metals such as iron/steel 27-29, copper ${ }^{30-32}$, and aluminium ${ }^{33-35}$ have been analyzed to understand the dynamics of their stock and flow in society. D-MFA further evaluates the implications of material efficiency improvements ${ }^{36}$ on climate change mitigation based on detailed stocks-flows modeling ${ }^{37-}$ 39, suggesting its importance because of the huge energy consumptions in bulk metal industries. In addition to bulk metals, recently, minor metals or so-called 'critical metals' such as indium and rare earth elements have been highlighted, due to their potential importance for decarbonization and concern about supply constraints ${ }^{40-44}$. Owing to this, growing number of studies explore the longterm availability of critical metals based on the demand outlook, and imply the potential supply constraints for the introduction of low-carbon technologies ${ }^{45-52}$. Yet, we are still leaving an important question unanswered: "What are the implications of critical metal supply constraints and circulation improvements on long-term low-carbon scenarios?" This oversight risks not understanding potential trade-offs and synergies between climate change mitigation and circular economy strategies -in particular for minor and critical metals due to the limited amount of consumed energy compared to bulk metals.

Herein, we take a step towards the integrated modeling of energy-materials scenarios by unifying D-MFA with low-carbon scenarios using linear programming to address this important, and as yet seemingly unanswered, question. Our proposed model internalizes critical metal demandsupply based on dynamic stock-flow modeling into the low-carbon scenario, enabling to quantify the impacts of constrained metal supply on technology deployments. This model further can capture the implications of circular economy strategies in the low-carbon transitions as it incorporates potential critical metal supply from both mines and end-of-life recycling. That is, critical metal cycles and lowcarbon transitions can be described in one modeling framework rather than one-way analyses integrating low-carbon technology scenarios with material demand forecasts. This examination could support a shift from independent strategies considering only one aspect to nexus strategies incorporating the idea of linkage between energy and resources, bringing about symbiosis of the energy and resource sectors that have hitherto been approached in isolation ${ }^{53}$. Among various technologies and metals, we focus on lithium which is essential for battery technologies applied in electric vehicles and has been identified as particularly critical in previous studies ${ }^{54-56}$. 
101

102

103

104

105

106

107

108

109

110

111

112

113

114

115

116

117

118

119

120

121

122

123

124

125

\section{Materials and Methods}

Figure 1 is an overview of the modeling framework proposed in this study, describing the longterm scenario of vehicle introduction under the possible metal demand-supply balance by integrating stock-flow dynamics model (a tool utilized to conduct D-MFA ${ }^{25}$ ) and linear programming, based on International Energy Agency (IEA) scenarios at a global scale ${ }^{2}$. Notably, our modeling framework is characterized by quantifying the extent to which critical metal supply constraints and circularity improvements affect long-term vehicle type choice and well-to-wheel $\mathrm{CO}_{2}$ emissions associated with vehicle operation. This helps to explore the long-term strategic planning for energy and materials in an integrated manner.

The linear programming and inflow-driven dynamics model ${ }^{23}$ are connected so that the critical metal demand and secondary supply from EoL batteries are changed dynamically in response to the optimized annual inflows of each vehicle type. The stock-driven dynamics model, identified on the left side of Figure 1, is linked with the IEA's long-term scenarios, and calculates the annual inflows of various types of vehicles (Internal Combustion Engine Vehicles (ICEVs), Hybrid Electric Vehicles (HEVs), Plug-In Hybrid Electric Vehicles (PHEVs), Battery Electric Vehicles (BEVs)) under climate change mitigation strategies that achieve the $" 2{ }^{\circ} \mathrm{C}$ target" 1 . This is used as a constraint on the maximum introduction growth rate of EVs (indicating HEV, PHEV and BEV) since new technologies cannot deploy rapidly due to a lack of production and operational infrastructure. Moreover, the Hubbert peak model ${ }^{57}$ predicts primary metal supply from natural ore up to 2050 based on historical production and Ultimately Recoverable Resources (URR), creating a supply limit in each year. Thus, this model can evaluate both critical metal demand-supply balance in the low-carbon scenario to achieve the $2{ }^{\circ} \mathrm{C}$ target and the feedback that supply constraints bring to low-carbon scenarios. Below, we describe each component in more detail.

\subsection{Description of Modeling Framework}

The primary variables in the linear programming are the annual inflows of each vehicle type $k$, which are determined to minimize objective function indicating cumulative well-to-wheel $\mathrm{CO}_{2}$ emissions $V\left(\mathrm{t}-\mathrm{CO}_{2}\right)$ for vehicle operation within the scenario period from year $l$ to $n$. (2015 to 2050):

$$
\operatorname{Min} V=\sum_{t=l}^{n} \sum_{k \in K} S_{k}(t) \theta_{k} \psi_{k} \phi_{k}(t)
$$

where $S_{k}(t)$ (cars) indicates stocks (on road) of vehicle type $k$ in year $t, \theta_{k}$ and $\psi_{k}$ are the annual mileage $(\mathrm{km} / \mathrm{yr})$ and fuel consumption $(\mathrm{J} / \mathrm{km})$ of vehicle $k$ respectively. $\phi_{k}(t)$ represents $\mathrm{CO}_{2}$ intensity $\left(\mathrm{t}-\mathrm{CO}_{2} / \mathrm{J}\right)$ for consuming fuels or electricity, which changes over time reflecting changes in the electricity technology mix.

In this case, $S_{k}(t)$ is calculated based on the inflow-driven dynamics model shown in equation (2).

$$
S_{k}(t)=S_{k}(t-1)+I_{k}(t)-\sum_{a=0}^{a_{\max }} I_{k}(t-a) g(a)
$$

where $I_{k}(t)$ (cars) indicates vehicle inflow in year $t$, and the final term on the right-side of the equation expresses vehicle outflows represented using lifetime distribution $g(a)$ (-) (a Weibull distribution is utilized here).

Three constraint equations are set as follows, which are the balance of total annual vehicle stocks, the introduction growth rate of EVs and the demand-supply balance of lithium. 
143

144

145

146

147

148

149

150

151

152

153

154

(A) Constraints on total stock balancing

We assume that the total stocks of vehicles are equivalent to the above IEA scenario:

$$
\sum_{k \in K} S_{k, i e a}(t)=\sum_{k \in K} S_{k}(t)
$$

(B) Constraints on growth rate of electric vehicles

It is well known that emerging technologies cannot diffuse rapidly in the market, but gradually expand by following a growth curve ${ }^{27}$. This study, therefore, sets constraints on the growth rate of EVs based on the 2 Degree Scenario (2DS) of the IEA which depicts the pathway to achieve the global $2{ }^{\circ} \mathrm{C}$ temperature rise target ${ }^{2}$ specified in the Paris agreement ${ }^{1}$.

$$
I_{k^{\prime}, \text { iea }}(t) \geq I_{k^{\prime}}(t)
$$

where $k^{\prime}$ indicates emerging vehicle types expressing HEVs, PHEVs and BEVs while $k$ includes ICEVs. Here, $I_{k^{\prime}, \text { iea }}(t)$ (cars) is calculated by the stock-driven dynamics model shown in equation (5).

$$
I_{k^{\prime}, i e a}(\mathrm{t})=S_{k^{\prime}, \text { iea }}(\mathrm{t})-S_{k^{\prime}, \text { iea }}(\mathrm{t}-1)+\sum_{a=0}^{a_{\max }} I_{k^{\prime}, \text { iea }}(t-a) g(a)
$$

155

156

157

158

159

160

161

162

163

164

165

166

167

168

169

170

171

\section{(C) Constraints of lithium demand-supply dynamics}

To quantify the implications of metal supply constraints and circulation improvements on longterm low-carbon scenarios, potential future supply should be modeled as an exogenous variable. However, there are no robust modeling frameworks to predict metal supply accurately, since it is determined by various complex factors such as market trends, price dynamics, and geopolitical factors. Under such circumstances, Hubbert peak theory ${ }^{57}$, defining that the annual production of finite natural resources resembles a symmetrical bell-shaped curve which eventually approaches zero as resources are depleted, has been considered relatively plausible, and been employed in many studies in recent years ${ }^{58-65}$. Therefore, the Hubber peak model was also used to estimate the future supply of lithium in this study.

Here, cumulative production $Q(t)$ up to year $t$ is expressed by equation (6).

$$
Q(t)=\frac{U R R}{1+e^{-r\left(t-t_{\max }\right)}}
$$

where URR denotes ultimately recoverable resources (tons) estimated by adding historical cumulative production and current known reserves (estimated to be $15 \mathrm{Mt}$ in this study), $t_{\max }$ (yr) is the year of peak production, and $r$ is the slope constant. When peak production is taken as $P_{\max }$, the URR can be expressed by equation (7).

$$
U R R=\frac{4 P_{\max }}{r}
$$

Therefore, global annual production from natural deposits in year $t$ is given by equation (8).

$$
P(t)=\frac{2 P_{\max }}{1+\cosh \left(r\left(t-t_{\max }\right)\right)}
$$

where $P_{\max }, t_{\max }$ and $r$ were determined by fitting to historical production from 1900-2016 using the least squares method and estimated to be as follows: $P_{\max }: 264(\mathrm{kt}), t_{\max }: 2058(\mathrm{yr})$ and $r: 0.07$ (-). 
In addition to primary production from mines, the potential amount of secondary supply recovered from EoL batteries $W(t)$ is estimated by equation (9) and assumes closed-loop recycling without losing functional quality 66 .

$$
W(t)=E O L R R_{k} M_{k}(t) \sum_{a=0}^{a_{\max }} I_{k}(t-a) g(a)
$$

where $M_{k}(t)$ is the lithium content (t/car) in vehicle $k$ and $E O L R R_{k}(\%)$ represents the EoL recycling rate ${ }^{67}$ of lithium, which is exogenously set according to the scenarios.

Finally, the lithium demand-supply balance constraint can be expressed by equation (10).

$$
\sum_{k \in K} M_{k}(t) I_{k}(t)+\text { Other }_{2016} \leq P(t)+W(t)
$$

where Other 2016 indicates lithium demand for non-EV applications, estimated by subtracting demand for EVs from total demand in 2016 and assumed to remain constant into the future.

\subsection{Data and Scenario Setting}

The modeling framework proposed in this study requires various statistical data on vehicles and metals (lithium in this study). Historical vehicle stock data from 1971 to 2015 were gathered from the literature 68,69 , and future stock up to 2050 under the $2{ }^{\circ} \mathrm{C}$ target was obtained from the 2DS ${ }^{2}$. The 2DS depicts a path to limit global temperature rise to $2{ }^{\circ} \mathrm{C}$ by 2100 , by assuming roll out of vehicles requiring an order-of-magnitude change in manufacturing of technology. In this scenario, the share of EVs on the road is indicated as $18 \%$ in 2030 (HEVs 7\%, PHEVs 6\%, BEVs 5\%) and $58 \%$ in 2050 (HEVs 16\%, PHEVs $24 \%$, BEVs 18\%). Although the deployment of fuel cell vehicles is also indicated in the 2DS, we have excluded it because of a lack of reliable data related to lithium use and well-towheel $\mathrm{CO}_{2}$ emissions and relatively small deployment $(0.3 \%$ in 2030 and $1 \%$ in 2050). The annual mileage and fuel consumption used to calculate $\mathrm{CO}_{2}$ emissions at the phase of vehicle operation and the $\mathrm{CO}_{2}$ intensity of each fuel were set with reference to the literature ${ }^{69,70}$. The $\mathrm{CO}_{2}$ intensity of electricity that drives EVs was set based on the 2DS, indicating decreases year by year, reflecting the increase in the percentage of renewable energy and other low-carbon technologies. Average lifetime and lifetime distribution of vehicles used in the stock-flow dynamics model were set with reference to the literature 27,33 .

The historical production of lithium during 1900-2016 was gathered from literature and databases ${ }^{71-73}$, and current known reserves were set based on the USGS database ${ }^{72}$. The lithium content of each vehicle type was set by calculating the average from various studies $40,51,74-77$. Note that lithium content may change year by year, reflecting technological development, such as more lithium intensive batteries (e.g., lithium-sulfur batteries ${ }^{78}$ ) or lithium-free batteries (e.g., sodium-ion batteries ${ }^{79}$ ). However, we assumed it to be static and constant in the future because of the large uncertainties. For the EoL recycling rate associated with circular economy strategies, three scenarios were set based on the literature ${ }^{80}$, namely, low recycling scenario $(0 \%)$, medium recycling scenario $(40 \%)$, and high recycling scenario $(80 \%)$. The indicated recycling rates were determined by the efficiency of the entire battery recycling chain and illustrate current, realistic, and optimistic cases, respectively ${ }^{81}$.

\subsection{Sensitivity Analysis}

Various parameters are undermined by uncertainties which potentially affect the results. Thus, we explore the impacts of our modeling assumptions by way of a sensitivity analysis. Investigated parameters are URR, metal content, and growth rate for non-EV applications.

First, identified reserves of lithium have been increasing year by year, representing a 4 -fold increase in 2016 from year 2000 amounts ${ }^{72}$. This is because the estimated value of reserves is 
determined by various parameters such as cost of extraction, price of metal, and technologies, which are changing over time. Since it is known that the value of URR has a substantial influence on the forecast of supply using the Hubbert peak model $58,65,71,82$, we predicted the lithium supply and re-ran the model in the case of $24 \mathrm{Mt}$ and $55 \mathrm{Mt}$ of URR, which were identified as best and maximum estimates, respectively, by Mohr et al ${ }^{71}$. Another important source of uncertainty is the lithium content of each vehicle type, which was set by calculating the average from multiple studies $40,51,74-77$. In these documents, BEV, for example, has a wide range of lithium content, from 2,400 to 12,700 g/car, suggesting huge uncertainty. Thus, we tested the implications of this on the outcomes by applying the maximum and minimum value in the literature (the uncertainty range is presented in Table S2 in the supporting information). Finally, the impact of the lithium demand scenario for non-EV applications was investigated, since other technologies, such as stationary energy storage and cell phones, might also require substantial amounts of lithium. We assumed here that demand from nonEV applications grows at the same rate of GDP in IEA's 2DS ${ }^{2}$ and at $5 \%$ based on a previous study 80.

\section{Results}

\subsection{Global Lithium Demand-Supply Balance to 2050}

Figure 2 shows the estimated lithium demand-supply balance up to 2050 based on the IEA's low-carbon scenario with potential recovery from EoL batteries, and indicates that supply constraints could occur from around 2030 without recycling, due to the rapid growth rate of EVs. Globally, lithium supply could continue to increase until 2058 and reach around $243 \mathrm{kt}$ in 2050 based on the Hubbert peak model, which is equivalent to around 6-fold higher than 2016. Lithium demand, however, could grow faster than supply, reaching $370 \mathrm{kt}$ in 2050, making supply constraints a real concern from a long-term perspective.

When we consider recycling from EoL batteries as well as primary supply from natural reserves, secondary supply fills most of the gap between demand and supply in the case of the high recycling scenario (assuming 80\% recycling rate), and total supply in 2050 could be increased to around $362 \mathrm{kt}$. Results also reveal that the demand-supply gap could not be filled even if achieving a $40 \%$ recycling rate during the modeled period, suggesting that supply constraints would become problematic from around 2035.

In reality, the rapid increase in lithium demand for EVs could stimulate investment in further development of mining and boost lithium supply from natural deposits. However, it should be emphasized that a substantial increase in mining activities, which greatly exceeds past rates of expansion, could be avoided by increasing the recycling rate to $80 \%$. This is an important perspective because lithium production from brine adversely affects access to clean water and spodumene generates a large amount of mine waste resulting in land transformation and vegetation destruction ${ }^{56}$. In this context, another important finding here is perhaps that EoL recycling has a small impact on boosting supply in a phase of exponential growth such as around 2030 even if the recycling rate is raised to $80 \%$. For example, secondary supply in the high recycling scenario only contributes $9 \%$ of total supply in 2030. In 2050, on the other hand, this value exceeds $30 \%$, implying that an EoL recycling-oriented strategy has little effect in the coming years. This is because the mass generation of discards lags the rapid increase in demand due to the fact that battery lifetime 'locks in' recycling potential into society. That is, an EoL-oriented strategy would be more crucial from a longterm perspective such as up to 2050 than in the short/medium term, in the case of emerging technologies including the lithium-ion battery. 
Figure 3 presents optimized introduction scenarios for each vehicle type under lithium demandsupply dynamics with different assumptions on EoL recycling rates up to 2050. The results show that the deployment of BEVs is restricted due to the lack of lithium supply and ICEV increases for that amount from around 2030 in the case of low and medium recycling scenarios compared to the high recycling scenario, in which the demand-supply gap is covered by secondary supply from EoL batteries. Here, the results reveal that HEVs and PHEVs with lower $\mathrm{CO}_{2}$ emissions per lithium usage $\left(\mathrm{CO}_{2} / \mathrm{Li}-\mathrm{t} / \mathrm{km}\right)$ are deployed preferentially over BEVs to minimize cumulative $\mathrm{CO}_{2}$ emissions in the scenario period under the lithium supply constraints. In reality, however, it is unrealistic for HEVs and PHEVs to be allowed to use the full lithium supply without constraints, and for BEVs to obtain the rest. It should therefore be noted that the lithium supply distribution has been automatically determined here to minimize cumulative well-to-wheel $\mathrm{CO}_{2}$ emissions in the scenario period rather than reflecting the real world.

The constrained BEV deployments lead to a difference in $\mathrm{CO}_{2}$ emissions for vehicle operation over time as shown in Figure 4, indicating that the low recycling scenario generates an additional 300 $\mathrm{Mt}-\mathrm{CO}_{2}$ in 2050 relative to the IEA scenario that does not consider the potential lithium demandsupply balance. This amount corresponds to around $16 \%$ of total emissions from passenger lightduty vehicles in 2050 in the 2DS, emphasizing the large impacts of constrained lithium supply on $\mathrm{CO}_{2}$ emissions. The results also imply that improving the EoL recycling rate to $40 \%$ could reduce this amount by $52 \%$, and a $99 \%$ reduction could be accomplished by an $80 \%$ recycling rate. These estimations highlight the implications of metal circulation improvements on low-carbon scenarios, which is an important contribution of this study brought about by ideas of integrating critical metal stock and flows into low-carbon forecasting. Importantly, the results of this study do not deny the mass deployment of EVs in the context of climate change mitigation, but underscore the importance of resource circulation improvements at the same or faster pace as EV introduction.

\subsection{Impacts of Parameters Uncertainty}

Figure 5 demonstrates the results of the sensitivity analysis expressed in terms of estimated inflows of each vehicle type up to 2050. The results clearly illustrate that the largest impact is driven by the lithium content of each vehicle type. In the case of employing the maximum value of lithium content obtained from the extant literature, the spread of BEVs is greatly restricted due to the constrained lithium supply, which also inhibits the introduction of PHEVs. Consequently, this scenario generates an additional $800 \mathrm{Mt}-\mathrm{CO}_{2}$ of emissions in 2050 compared to the IEA scenario, which is equivalent to $40 \%$ of total emissions from passenger light-duty vehicles in the 2DS. When assuming the minimum value, on the other hand, no EVs restrictions can be confirmed, and thus there are no additional $\mathrm{CO}_{2}$ emissions. Furthermore, we can also observe that our modeling framework has a high sensitivity to URR and demand growth rate for non-EV applications. These assumptions are intrinsically uncertain, but the sensitivity analysis performed herein underscores the necessity of further scientific efforts to integrate energy and materials scenarios more robustly. This might include the development of a metal content database, metal supply projection models incorporating demand-supply interaction and market price dynamics, and various product dissemination scenarios.

\section{Discussion}

\subsection{Need to Integrate Critical Metal Cycles into Low-Carbon Scenarios}

This study quantitatively demonstrates that the rapid growth in lithium demand causes demand-supply imbalance up to 2050, which impedes the deployment of BEVs and consequently increases $\mathrm{CO}_{2}$ emissions. Alarmingly, the $2^{\circ} \mathrm{C}$ target specified in the Paris agreement demands substantial improvements in critical metal circulation in the transport sector. This perspective firmly 
suggests the necessity of internalization of critical metal flows and stocks in low-carbon scenarios to highlight synergies and trade-offs between climate change mitigation and circular economy strategies. Despite the importance of this work, existing scenario reports on climate change, including the IPCC's 5th Assessment Report 3, the IEA's World Energy Outlook 83, and Energy Technology Perspectives ${ }^{2}$, have not successfully incorporated it so far. In other words, the path towards the lowcarbon society specified in these scenarios is heavily reliant on the suspicious assumption that natural resource supply in substantial quantities is possible over the long term, up to 2050 or even 2100. Again, we revealed that this assumption is problematic, as many others have previously stated ${ }^{45-52}$, and a low-carbon transition cannot be achieved without substantial improvements in EoL recycling rates. Thus, we argue that minor or critical metal cycles should be embodied in the discussion of climate change mitigation in addition to energy-intensive materials cycles such as those of iron and aluminium.

\subsection{Limited Impacts of EoL-Oriented Strategies in the Short/Medium Term}

Another important finding of this study is that EoL recycling of lithium-ion batteries has limited impacts on short/medium-term lithium demand-supply balance while being important from a longterm perspective to ensure sufficient supply for batteries in electric vehicles. This finding implies that strategies other than those which are EoL-oriented should be actively examined in the coming years that are expected to be an exponential growth stage. Nevertheless, several companies have been looking for business opportunities focused on the EoL stage. For example, Toyota has created incentives for customers to return their batteries at EoL ${ }^{84}$ and Renault is involved with a number of projects on the reuse of batteries once they reach EoL in EVs, such as reuse for stationary energy storage ${ }^{85}$. Needless to say, these attempts are critically important in the creation of a circular economy, but it should be recognized that there is a time lag between a rapid increase in demand and the generation of a certain amount of waste, as shown in this study. In this context, various strategies, not just focusing on EoL phases, should be investigated, such as improvements in loss in the manufacturing phases through recovering process scrap and car-sharing contributing to a reduction in overall vehicle demand.

\subsection{Future Research Directions}

In terms further research in this domain, modeling full life-cycle $\mathrm{CO}_{2}$ emissions considering the future electricity technology mix and primary and secondary metal supply dynamics could be an important task, although it would call for complex system descriptions and myriad assumptions to analyze the stocks and flows of all the metals required in vehicles. Modeling an advanced recycling system, one which enables achievement of a high recycling rate, is also required, as such a system likely demands additional energy consumption leading to increased $\mathrm{CO}_{2}$ emissions. In this regard, it would be worth investigating the optimal dual variable corresponding to Equation (10), which shows how much $\mathrm{CO}_{2}$ emissions could be reduced when the right-hand side of Equation (10) increases by 1 t. To better understand the implications of integrated simulation of energy-materials scenarios, furthermore, social-environmental consequences associated with critical material supply should be internalized in the model in addition to the physical demand-supply dynamics examined in this study. Namely, it would be important to consider and manage various impacts accompanying mining activities, including damage to ecosystems in terms of mine waste ${ }^{86}$, water risk 87 , and biodiversity loss ${ }^{88}$ and social factors such as health damage and human rights 89,90 , as responsible sourcing would be increasingly required in the coming decades ${ }^{91}$. These attempts would allow for informed discussions of trade-offs and synergies between resource circulation and climate change from broader perspectives. 
NOTES: The authors declare no conflict of interest

370

371

372

373

374

375

ACKNOWLEDGMENTS: This research was supported in part by Grants-in-Aid for Research (No. 18KT0056, 18KT0010 and 19K24391) from the Japanese Ministry of Education, Culture, Sports, Science and Technology. We thank Wataru Takayanagi for drafting the graphical abstract and providing helpful comments about the figures used in this paper.

\section{References}

(1) UNFCCC. ADOPTION OF THE PARIS AGREEMENT; Report No. FCCC/CP/2015/L.9/Rev.1; 2015. https://doi.org/10.1007/BF02327128.

(2) IEA. Energy Technology Perspectives 2017: Catalysing Energy Technology Transformations Together Secure Sustainable; Paris, France, 2017. https://doi.org/10.1787/energy_tech-2017-en.

(3) IPCC. Climate Change 2014: Mitigation of Climate Change; United Kingdom and New York, NY, USA, 2014. https://doi.org/10.1017/CBO9781107415416.

(4) Vidal, O.; Goffé, B.; Arndt, N. Metals for a Low-Carbon Society. Nat. Geosci. 2013, 6 (11), 894-896. https://doi.org/10.1038/ngeo1993.

(5) Watari, T.; Mclellan, B. C.; Giurco, D.; Dominish, E.; Yamasue, E.; Nansai, K. Total Material Requirement for the Global Energy Transition to 2050: A Focus on Transport and Electricity. Resour. Conserv. Recycl. 2019, 148 (May), 91-103. https://doi.org/10.1016/j.resconrec.2019.05.015.

(6) Davidsson, S.; Höök, M.; Wall, G. A Review of Life Cycle Assessments on Wind Energy Systems. Int. J. Life Cycle Assess. 2012, 17 (6), 729-742. https://doi.org/10.1007/s11367-012-0397-8.

(7) Gerbinet, S.; Belboom, S.; Léonard, A. Life Cycle Analysis (LCA) of Photovoltaic Panels: A Review.

(8) Asdrubali, F.; Baldinelli, G.; D’Alessandro, F.; Scrucca, F. Life Cycle Assessment of Electricity Production from Renewable Energies: Review and Results Harmonization. Renew. Sustain. Energy Rev. 2015, 42, 1113-1122. https://doi.org/10.1016/j.rser.2014.10.082.

(9) Hawkins, T. R.; Gausen, O. M.; Strømman, A. H. Environmental Impacts of Hybrid and Electric Vehicles-a Review. Int. J. Life Cycle Assess. 2012, 17 (8), 997-1014. https://doi.org/10.1007/s11367-0120440-9.

(10) Hawkins, T. R.; Singh, B.; Majeau-Bettez, G.; Strømman, A. H. Comparative Environmental Life Cycle Assessment of Conventional and Electric Vehicles. J. Ind. Ecol. 2013, 17 (1), 53-64. https://doi.org/10.1111/j.1530-9290.2012.00532.x.

(11) Mendoza Beltran, A.; Cox, B.; Mutel, C.; van Vuuren, D. P.; Font Vivanco, D.; Deetman, S.; Edelenbosch, O. Y.; Guinée, J.; Tukker, A. When the Background Matters: Using Scenarios from Integrated Assessment Models in Prospective Life Cycle Assessment. J. Ind. Ecol. 2018, 00 (0), 1-16. https://doi.org/10.1111/jiec.12825.

(12) Arvidsson, R.; Tillman, A. M.; Sandén, B. A.; Janssen, M.; Nordelöf, A.; Kushnir, D.; Molander, S. Environmental Assessment of Emerging Technologies: Recommendations for Prospective LCA. J. Ind. Ecol. 2018, 22 (6), 1286-1294. https://doi.org/10.1111/jiec.12690.

(13) Arvesen, A.; Luderer, G.; Pehl, M.; Bodirsky, B. L.; Hertwich, E. G. Deriving Life Cycle Assessment Coefficients for Application in Integrated Assessment Modelling. Environ. Model. Softw. 2018, 99, 111125. https://doi.org/10.1016/j.envsoft.2017.09.010. 
(14) Hertwich, E. G.; Gibon, T.; Bouman, E. A.; Arvesen, A.; Suh, S.; Heath, G. A.; Bergesen, J. D.; Ramirez, A.; Vega, M. I.; Shi, L. Integrated Life-Cycle Assessment of Electricity-Supply Scenarios Confirms Global Environmental Benefit of Low-Carbon Technologies. Proc. Natl. Acad. Sci. U. S. A. 2015, 112 (20), 6277-6282. https://doi.org/10.1073/pnas.1312753111.

(15) Pehnt, M. Dynamic Life Cycle Assessment (LCA) of Renewable Energy Technologies. Renew. Energy 2006, 31 (1), 55-71. https://doi.org/10.1016/j.renene.2005.03.002.

(16) Boubault, A.; Kang, S.; Maïzi, N. Closing the TIMES Integrated Assessment Model (TIAM-FR) Raw Materials Gap with Life Cycle Inventories. J. Ind. Ecol. 2018, 00 (0), 1-14. https://doi.org/10.1111/jiec.12780.

(18) Boubault, A.; Maïzi, N. Devising Mineral Resource Supply Pathways to a Low-Carbon Electricity

(19) European Commision. Closing the Loop - An EU Action Plan for the Circular Economy; Brussels, Belgium.,

(20) Liu, J.; Hull, V.; Godfray, H. C. J.; Tilman, D.; Gleick, P.; Hoff, H.; Pahl-Wostl, C.; Xu, Z.; Chung, M. G.; Sun, J.; et al. Nexus Approaches to Global Sustainable Development. Nat. Sustain. 2018, 1 (9), 466-476. https://doi.org/10.1038/s41893-018-0135-8.

(21) Bleischwitz, R.; Spataru, C.; VanDeveer, S. D.; Obersteiner, M.; van der Voet, E.; Johnson, C.; AndrewsSustainable Development Goals. Nat. Sustain. 2018, 1 (December), 737-743. https://doi.org/10.1038/s41893-018-0173-2.

(23) Wiedenhofer, D.; Fishman, T.; Lauk, C.; Haas, W.; Krausmann, F. Integrating Material Stock Dynamics

(24) Krausmann, F.; Lauk, C.; Haas, W.; Wiedenhofer, D. From Resource Extraction to Outflows of Wastes and Emissions: The Socioeconomic Metabolism of the Global Economy, 1900-2015. Glob. Environ.

(26) Krausmann, F.; Wiedenhofer, D.; Lauk, C.; Haas, W.; Tanikawa, H.; Fishman, T.; Miatto, A.; Schandl, Chang. 2018, 52 (December 2017), 131-140. https://doi.org/10.1016/j.gloenvcha.2018.07.003. Into Economy-Wide Material Flow Accounting: Concepts, Modelling, and Global Application for 1900-2050. Ecol. Econ. 2019, 156, 121-133. https://doi.org/10.1016/j.ecolecon.2018.09.010. Müller, E.; Hilty, L. M.; Widmer, R.; Schluep, M.; Faulstich, M. Modeling Metal Stocks and Flows: A Review of Dynamic Material Flow Analysis Methods. Environ. Sci. Technol. 2014, 48 (4), 2102-2113. https://doi.org/10.1021/es403506a. H.; Haberl, H. Global Socioeconomic Material Stocks Rise 23-Fold over the 20th Century and Require Half of Annual Resource Use. Proc. Natl. Acad. Sci. 2017, 114 (8), 1880-1885. https://doi.org/10.1073/pnas.1613773114.

Hatayama, H.; Daigo, I.; Matsuno, Y.; Adachi, Y. Outlook of the World Steel Cycle Based on the Stock and Flow Dynamics. Environ. Sci. Technol. 2010, 44 (16), 6457-6463. https://doi.org/10.1021/es100044n. Müller, D. B.; Wang, T.; Duval, B. Patterns of Iron Use in Societal Evolution. Environ. Sci. Technol. 2011, 45 (1), 182-188. https://doi.org/10.1021/es102273t. 
(29) Pauliuk, S.; Wang, T.; Müller, D. B. Steel All over the World: Estimating in-Use Stocks of Iron for 200 Countries. Resour. Conserv. Recycl. 2013, 71, 22-30. https://doi.org/10.1016/j.resconrec.2012.11.008.

(30) Glöser, S.; Soulier, M.; Tercero Espinoza, L. A. Dynamic Analysis of Global Copper Flows. Global Stocks, Postconsumer Material Flows, Recycling Indicators, and Uncertainty Evaluation. Environ. Sci. Technol. 2013, 47 (12), 6564-6572. https://doi.org/10.1021/es400069b.

(31) Daigo, I.; Hashimoto, S.; Matsuno, Y.; Adachi, Y. Material Stocks and Flows Accounting for Copper and Copper-Based Alloys in Japan. Resour. Conserv. Recycl. 2009, 53 (4), 208-217. https://doi.org/10.1016/j.resconrec.2008.11.010.

(32) Spatari, S.; Bertram, M.; Gordon, R. B.; Henderson, K.; Graedel, T. E. Twentieth Century Copper Stocks and Flows in North America: A Dynamic Analysis. Ecol. Econ. 2005, 54 (1), 37-51. https://doi.org/10.1016/j.ecolecon.2004.11.018.

(33) Hatayama, H.; Daigo, I.; Matsuno, Y.; Adachi, Y. Evolution of Aluminum Recycling Initiated by the Introduction of Next-Generation Vehicles and Scrap Sorting Technology. Resour. Conserv. Recycl. 2012, 66, 8-14. https://doi.org/10.1016/j.resconrec.2012.06.006.

(34) Chen, W. Q.; Graedel, T. E. Dynamic Analysis of Aluminum Stocks and Flows in the United States: 1900-2009. Ecol. Econ. 2012, 81, 92-102. https://doi.org/10.1016/j.ecolecon.2012.06.008.

(35) Liu, G.; Müller, D. B. Centennial Evolution of Aluminum In-Use Stocks on Our Aluminized Planet. Environ. Sci. Technol. 2013, 47 (9), 4882-4888. https://doi.org/10.1021/es305108p.

(36) Allwood, J. M.; Ashby, M. F.; Gutowski, T. G.; Worrell, E. Material Efficiency: Providing Material Services with Less Material. Philos. Trans. R. Soc. A 2013, 371, 20120496.

(37) Pauliuk, S.; Müller, D. B. The Role of In-Use Stocks in the Social Metabolism and in Climate Change Mitigation. Glob. Environ. Chang. 2014, 24 (1), 132-142. https://doi.org/10.1016/j.gloenvcha.2013.11.006.

(38) Liu, G.; Bangs, C.; Müller, D. B. Stock Dynamics and Emission Pathways of the Global Aluminum Cycle. Nat. Clim. Chang. 2013, 3 (4), 178. https://doi.org/10.1002/9781118679401.ch46.

(39) Milford, R. L.; Pauliuk, S.; Allwood, J. M.; Müller, D. B. The Roles of Energy and Material Efficiency in Meeting Steel Industry CO2 Targets. Environ. Sci. Technol. 2013, 47 (7), 3455-3462. https://doi.org/10.1021/es3031424.

(40) U.S. Department of Energy. Critical Materials Strategy: 2011; Washington, DC, USA, 2011. https://doi.org/DOE/PI-0009.

(41) Moss, R.; Tzimas, E.; Willis, P.; Arendorf, J.; Tercero Espinoza, L.; Thomson, P.; Chapman, A.; Morley, N.; Sims, E.; Bryson, R.; et al. Critical Metals in the Path towards the Decarbonisation of the EU Energy Sector; 2013. https://doi.org/10.2790/46338.

(42) Roelich, K.; Dawson, D. A.; Purnell, P.; Knoeri, C.; Revell, R.; Busch, J.; Steinberger, J. K. Assessing the Dynamic Material Criticality of Infrastructure Transitions: A Case of Low Carbon Electricity. Appl. Energy 2014, 123, 378-386. https://doi.org/10.1016/j.apenergy.2014.01.052.

(43) Helbig, C.; Bradshaw, A. M.; Wietschel, L.; Thorenz, A.; Tuma, A. Supply Risks Associated with Lithium-Ion Battery Materials. J. Clean. Prod. 2018, 172, 274-286. https://doi.org/10.1016/j.jclepro.2017.10.122.

(44) Helbig, C.; Bradshaw, A. M.; Kolotzek, C.; Thorenz, A.; Tuma, A. Supply Risks Associated with CdTe and CIGS Thin-Film Photovoltaics. Appl. Energy 2016, 178, 422-433.

https://doi.org/10.1016/j.apenergy.2016.06.102. 
(45) de Koning, A.; Kleijn, R.; Huppes, G.; Sprecher, B.; van Engelen, G.; Tukker, A. Metal Supply Constraints for a Low-Carbon Economy? Resour. Conserv. Recycl. 2018, 129 (October 2017), 202-208. https://doi.org/10.1016/j.resconrec.2017.10.040.

(46) Elshkaki, A.; Graedel, T. E. Dynamic Analysis of the Global Metals Flows and Stocks in Electricity Generation Technologies. J. Clean. Prod. 2013, 59, 260-273. https://doi.org/10.1016/j.jclepro.2013.07.003.

(47) Watari, T.; McLellan, B.; Ogata, S.; Tezuka, T. Analysis of Potential for Critical Metal Resource Constraints in the International Energy Agency's Long-Term Low-Carbon Energy Scenarios. Minerals 2018, 8 (156). https://doi.org/10.3390/min8040156.

(48) Grandell, L.; Lehtilä, A.; Kivinen, M.; Koljonen, T.; Kihlman, S.; Lauri, L. S. Role of Critical Metals in the Future Markets of Clean Energy Technologies. Renew. Energy 2016, 95, 53-62. https://doi.org/10.1016/j.renene.2016.03.102.

(49) Kavlak, G.; McNerney, J.; Jaffe, R. L.; Trancik, J. E. Metal Production Requirements for Rapid Photovoltaics Deployment. Energy Environ. Sci. 2015, 8 (6), 1651-1659. https://doi.org/10.1039/c5ee00585j.

(50) Månberger, A.; Stenqvist, B. Global Metal Flows in the Renewable Energy Transition: Exploring the Effects of Substitutes, Technological Mix and Development. Energy Policy 2018, 119 (0), 226-241. https://doi.org/10.1016/j.enpol.2018.04.056.

(51) Valero, A.; Valero, A.; Calvo, G.; Ortego, A. Material Bottlenecks in the Future Development of Green Technologies. Renew. Sustain. Energy Rev. 2018, 93 (March 2017), 178-200. https://doi.org/10.1016/j.rser.2018.05.041.

(52) Alonso, E.; Sherman, A. M.; Wallington, T. J.; Everson, M. P.; Field, F. R.; Roth, R.; Kirchain, R. E. Evaluating Rare Earth Element Availability: A Case with Revolutionary Demand from Clean Technologies. Environ. Sci. Technol. 2012, 46 (6), 3406-3414. https://doi.org/10.1021/es203518d.

(53) Giurco, D.; McLellan, B.; Franks, D. M.; Nansai, K.; Prior, T. Responsible Mineral and Energy Futures: Views at the Nexus. J. Clean. Prod. 2014, 84 (1), 322-338. https://doi.org/10.1016/j.jclepro.2014.05.102.

(54) Prior, T.; Wäger, P. A.; Stamp, A.; Widmer, R.; Giurco, D. Sustainable Governance of Scarce Metals: The Case of Lithium. Sci. Total Environ. 2013, 461-462, 785-791. https://doi.org/10.1016/j.scitotenv.2013.05.042.

(55) Olivetti, E. A.; Ceder, G.; Gaustad, G. G.; Fu, X. Lithium-Ion Battery Supply Chain Considerations: Analysis of Potential Bottlenecks in Critical Metals. Joule 2017, 1 (2), 229-243. https://doi.org/10.1016/j.joule.2017.08.019.

(56) Florin, N.; Dominish, E. Sustainability Evaluation of Energy Storage Technologies; 2017.

(57) Hubbert, M. K. Nuclear Energy and the Fossil Fuels. Drill. Prod. Pract. 1956, 95, 1-57.

(58) Calvo, G.; Valero, A.; Valero, A. Assessing Maximum Production Peak and Resource Availability of Non-Fuel Mineral Resources: Analyzing the Influence of Extractable Global Resources. Resour. Conserv. Recycl. 2017, 125 (June), 208-217. https://doi.org/10.1016/j.resconrec.2017.06.009.

(59) Mohr, S.; Giurco, D.; Retamal, M.; Mason, L.; Mudd, G. Global Projection of Lead-Zinc Supply from Known Resources. Resources 2018, 7 (1), 17. https://doi.org/10.3390/resources7010017.

(60) Prior, T.; Daly, J.; Mason, L.; Giurco, D. Resourcing the Future: Using Foresight in Resource Governance. Geoforum 2013, 44, 316-328. https://doi.org/10.1016/j.geoforum.2012.07.009.

(61) Giurco, D.; Mohr, S.; Mudd, G.; Mason, L.; Prior, T. Resource Criticality and Commodity Production Projections. Resources 2012, 1 (1), 23-33. https://doi.org/10.3390/resources1010023. 
(62) Prior, T.; Giurco, D.; Mudd, G.; Mason, L.; Behrisch, J. Resource Depletion, Peak Minerals and the Implications for Sustainable Resource Management. Int. Soc. Ecol. Econ. 2007, 1-20. https://doi.org/10.1016/j.gloenvcha.2011.08.009.

(63) Meinert, L.; Robinson, G.; Nassar, N. Mineral Resources: Reserves, Peak Production and the Future. Resources 2016, 5 (1), 14. https://doi.org/10.3390/resources5010014.

(64) Tilton, J. E. The Hubbert Peak Model and Assessing the Threat of Mineral Depletion. Resour. Conserv. Recycl. 2018, 139 (July), 280-286. https://doi.org/10.1016/j.resconrec.2018.08.026.

(65) Vikström, H.; Davidsson, S.; Höök, M. Lithium Availability and Future Production Outlooks. Appl. Energy 2013, 110, 252-266. https://doi.org/10.1016/j.apenergy.2013.04.005.

(66) Nakamura, S.; Kondo, Y.; Kagawa, S.; Matsubae, K.; Nakajima, K.; Nagasaka, T. MaTrace: Tracing the Fate of Materials over Time and across Products in Open-Loop Recycling. Environ. Sci. Technol. 2014, 48 (13), 7207-7214. https://doi.org/10.1021/es500820h.

(67) UNEP. Recycling Rates of Metals - A Status Report, A Report of the Working Group on the Global Metal Flows

(68) The Institute of Energy Economics Japan. EDMC Handbook of Japan's \& World Energy E Economic

IEA. Global EV Outlook 2018; Paris, France, 2018. https://doi.org/10.1787/9789264302365-en.

(70) IEA. Energy Technology Systems Analysis Programme; Paris, France, 2010. https://doi.org/10.1007/978-3319-18639-9.

(71) Mohr, S. H.; Mudd, G. M.; Giurco, D. Lithium Resources and Production: Critical Assessment and Global Projections. Minerals 2012, 2 (1), 65-84. https://doi.org/10.3390/min2010065. U.S. Geological Survey. Commodity Statistics and Information https://minerals.usgs.gov/minerals/pubs/mcs/. https://www.bgs.ac.uk/mineralsuk/statistics/wms.cfc?method=searchWMS.

Fishman, T.; Myers, R.; Rios, O.; Graedel, T. E. Implications of Emerging Vehicle Technologies on Rare Earth Supply and Demand in the United States. Resources 2018, 7 (1), 9. https://doi.org/10.3390/resources7010009.

(75) Moss, R. L.; Tzimas, E.; Willis, P.; Arendorf, J. Critical Metals in the Path towards the Decarbonisation of the EU Energy Sector; Brussels, Belgium, 2013. https://doi.org/10.2790/46338.

(76) The Growing Role of Minerals and Metals for a Low Carbon Future. 2017, No. June. https://doi.org/10.1596/28312.

568 (77) Rutherford, T. F. A Lithium Shortage : Are Electric Vehicles Under Threat? 2011, No. May.

(78) Giurco, D.; Dominish, E.; Florin, N.; Watari, T.; McLellan, B. Requirements for Minerals and Metals for 100\% Renewable Scenarios. In Achieving the Paris Climate Agreement Goals: Global and Regional 100\% Renewable Energy Scenarios with Non-Energy GHG Pathways for $+1.5 \mathrm{C}$ and +2 C; 2019. https://doi.org/10.1007/978-3-030-05843-2_11.

(79) Tanibata, N.; Kondo, Y.; Yamada, S.; Maeda, M.; Takeda, H.; Nakayama, M.; Asaka, T.; Kitajou, A.; Okada, S. Nanotube-Structured Na 2 V 3 O 7 as a Cathode Material for Sodium-Ion Batteries with High-Rate and Stable Cycle Performances. Sci. Rep. 2018, 8 (1), 6-12. https://doi.org/10.1038/s41598-01835608-9. 
(80) Ziemann, S.; Müller, D. B.; Schebek, L.; Weil, M. Modeling the Potential Impact of Lithium Recycling from EV Batteries on Lithium Demand: A Dynamic MFA Approach. Resour. Conserv. Recycl. 2018, 133 (July 2017), 76-85. https://doi.org/10.1016/j.resconrec.2018.01.031.

(81) Weil, M.; Ziemann, S. Recycling of Traction Batteries as a Challenge and Chance for Future Lithium Availability. Lithium-Ion Batter. 2014, 509-528. https://doi.org/10.1016/B978-0-444-59513-3.00022-4.

(82) Northey, S.; Mohr, S.; Mudd, G. M.; Weng, Z.; Giurco, D. Modelling Future Copper Ore Grade Decline Based on a Detailed Assessment of Copper Resources and Mining. Resour. Conserv. Recycl. 2014, 83, 190-201. https://doi.org/10.1016/j.resconrec.2013.10.005.

(83) IEA. World Energy Outlook 2018; Paris, France, 2018. https://doi.org/10.1049/ep.1977.0180.

586 (84) Dominish, E.; Teske, S.; Florin, N. Responsible Minerals Sourcing for Renewable Energy Research; 2019.

(85) Renault. Renault optimizes the lifecycle of its electric vehicle batteries.

(86) Mudd, G. M. The Environmental Sustainability of Mining in Australia: Key Mega-Trends and Looming Constraints. Resour. Policy 2010, 35 (2), 98-115. https://doi.org/10.1016/j.resourpol.2009.12.001.

Northey, S. A.; Mudd, G. M.; Werner, T. T.; Jowitt, S. M.; Haque, N.; Yellishetty, M.; Weng, Z. The Exposure of Global Base Metal Resources to Water Criticality, Scarcity and Climate Change. Glob. Environ. Chang. 2017, 44 (March), 109-124. https://doi.org/10.1016/j.gloenvcha.2017.04.004.

(88) Sonter, L. J.; Ali, S. H.; Watson, J. E. M. Mining and Biodiversity_Key Issues and Research Needs in Conservation Science. Proc. R. Soc. B Biol. Sci. 2018, 285. https://doi.org/http://doi.org/10.1098/rspb.2018.1926. Banza Lubaba Nkulu, C.; Casas, L.; Haufroid, V.; De Putter, T.; Saenen, N. D.; Kayembe-Kitenge, T.; Musa Obadia, P.; Kyanika Wa Mukoma, D.; Lunda Ilunga, J. M.; Nawrot, T. S.; et al. Sustainability of A.; Kinnaird, J.; Littleboy, A.; et al. Mineral Supply for Sustainable Development Requires Resource Governance. Nature 2017, 543 (7645), 367-372. https://doi.org/10.1038/nature21359. Artisanal Mining of Cobalt in DR Congo. Nat. Sustain. 2018, 1 (9), 495-504. https://doi.org/10.1038/s41893-018-0139-4. Mancini, L.; Sala, S. Social Impact Assessment in the Mining Sector: Review and Comparison of Indicators Frameworks. Resour. Policy 2018, 57 (February), 98-111. https://doi.org/10.1016/j.resourpol.2018.02.002. 


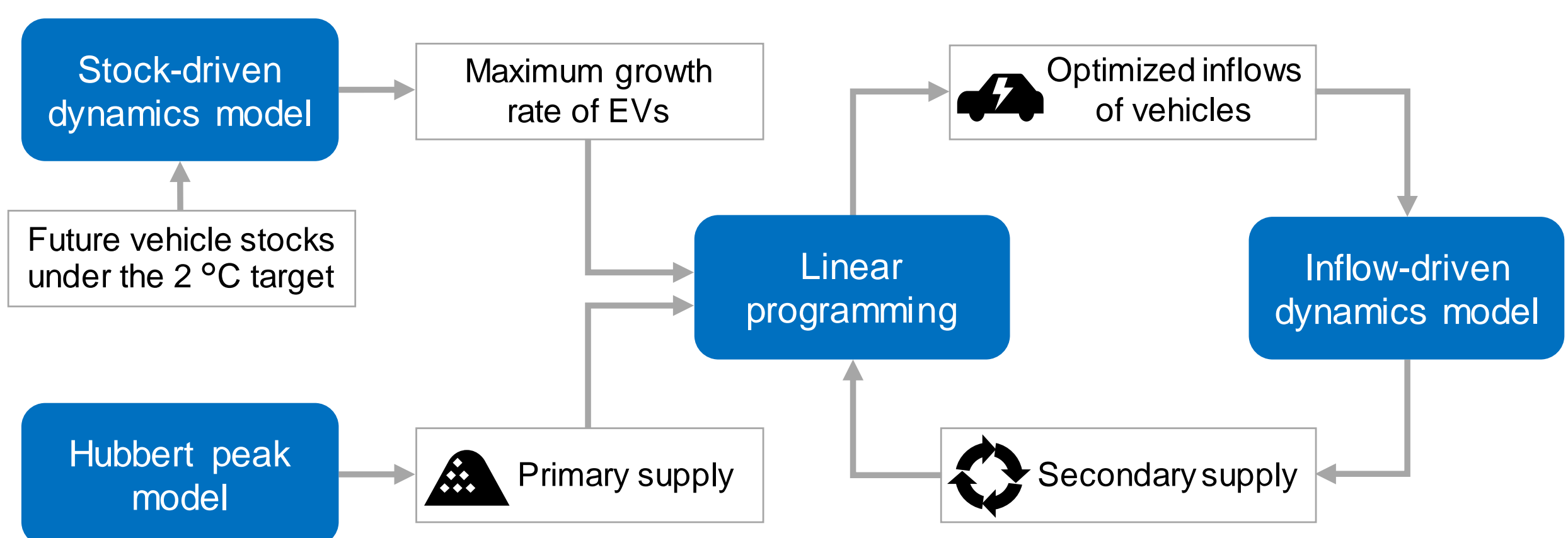

Figure 1. Overview of the modeling framework to develop integrated scenarios of energy and materials. Annual inflows of each vehicle type up to 2050 are successively determined to minimize cumulative well-to-wheel $\mathrm{CO}_{2}$ emissions for vehicle operation, under the condition of annual metal production from the Hubbert peak model and growth rate of electric vehicles from the stock-driven dynamics model linking to the IEA's 2 Degree Scenario. The linear programming and inflow-driven dynamics model are connected so that critical metal demand and secondary supply from EoL batteries change dynamically in response to the 


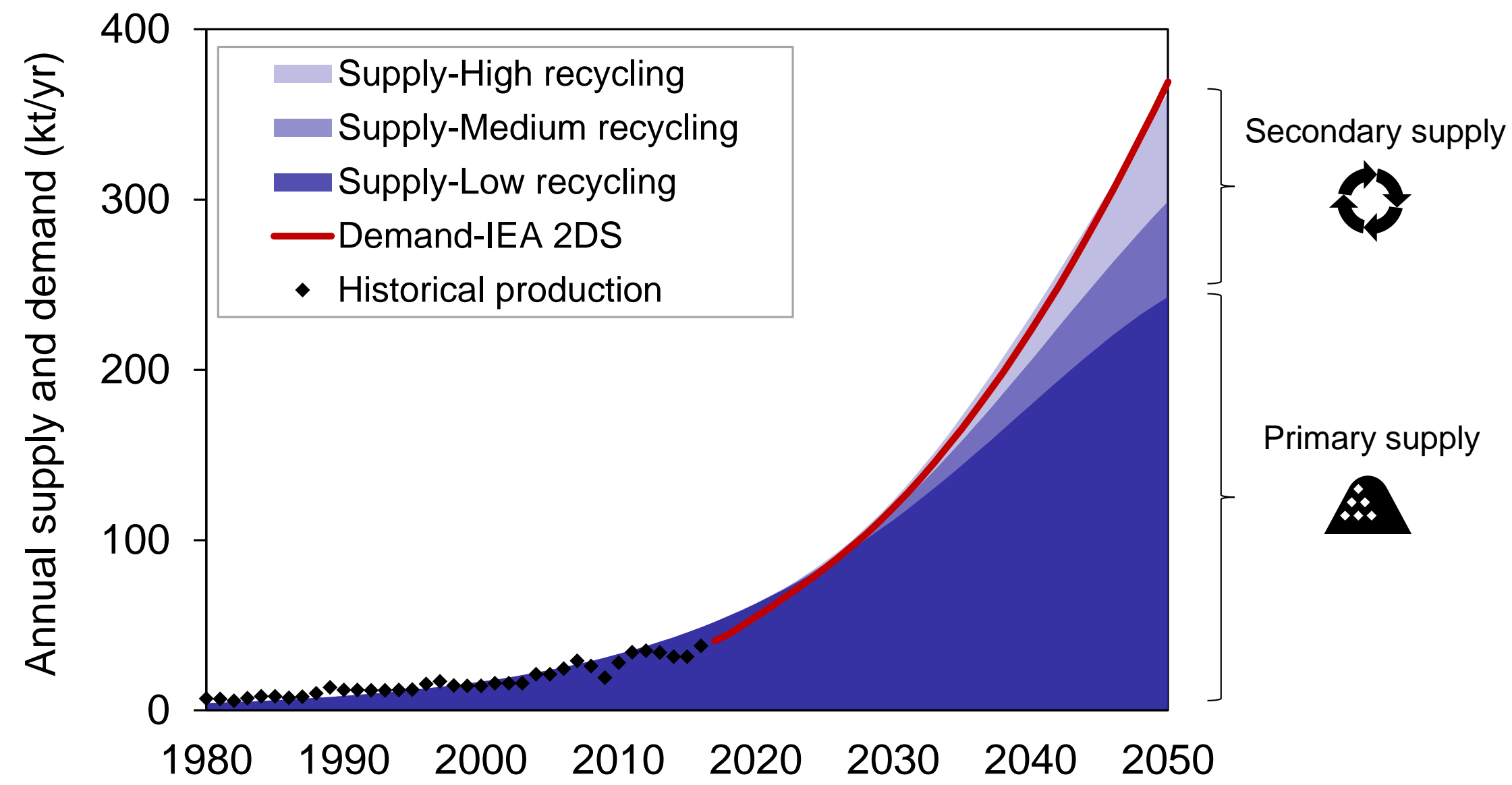

616 Figure 2. Predicted lithium demand-supply balance up to 2050, suggesting that supply constraints could occur from around 2030 without secondary supply from 617 recycled material. Supply-Low, Medium and High recycling scenarios assume $0 \%, 40 \%$ and $80 \%$ recycling rates respectively. Demand-IEA 2 DS represents the 


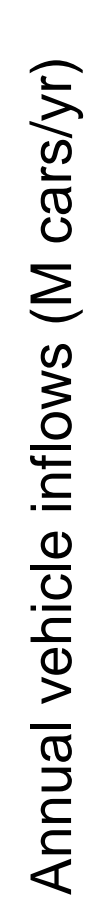

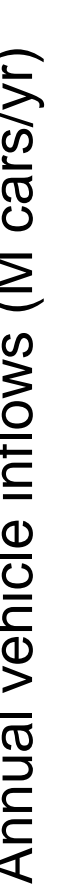

80
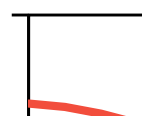

60

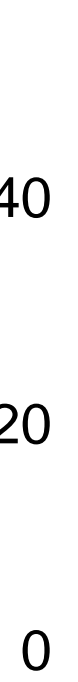

0

\section{Ranges in 2050}

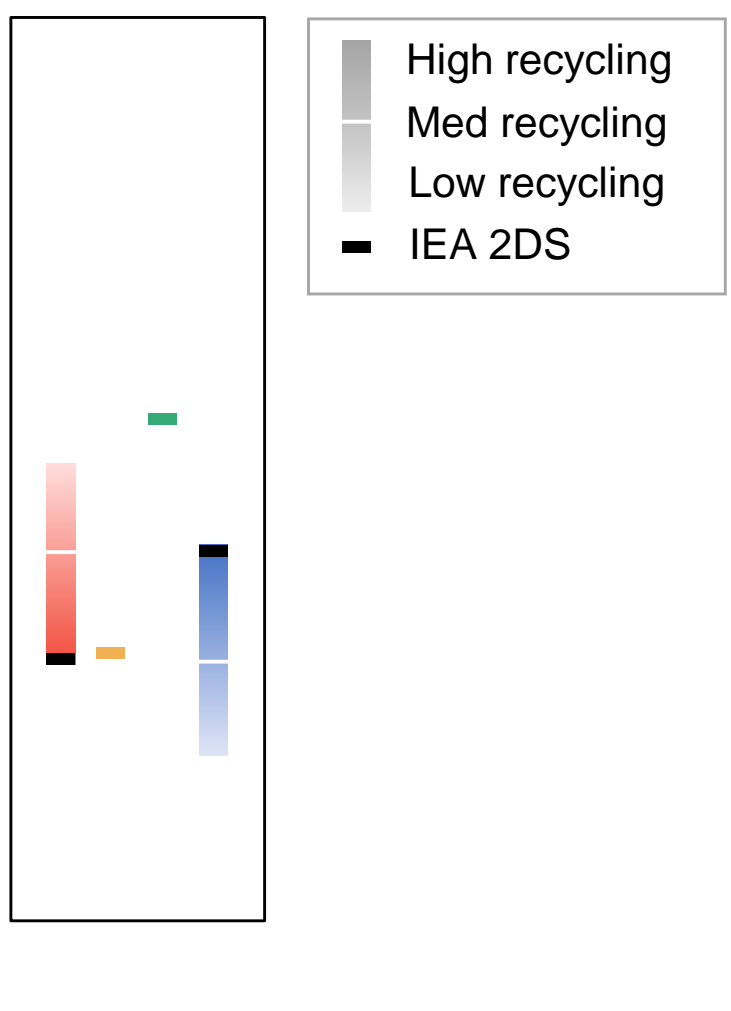

Figure 3. Estimated inflows of each vehicle type (ICEV: Internal Combustion Engine Vehicles, HEV: Hybrid Electric Vehicles, PHEV: Plug-In Hybrid Electric Vehicles, BEV: Battery Electric Vehicles) up to 2050 under lithium demand-supply dynamics with different assumptions of end-of-life (EoL) recycling rates. Low, Med and High recycling scenarios assume $0 \%, 40 \%$ and $80 \%$ recycling rates respectively. Shaded areas represent ranges due to the EoL recycling rate and the bar 


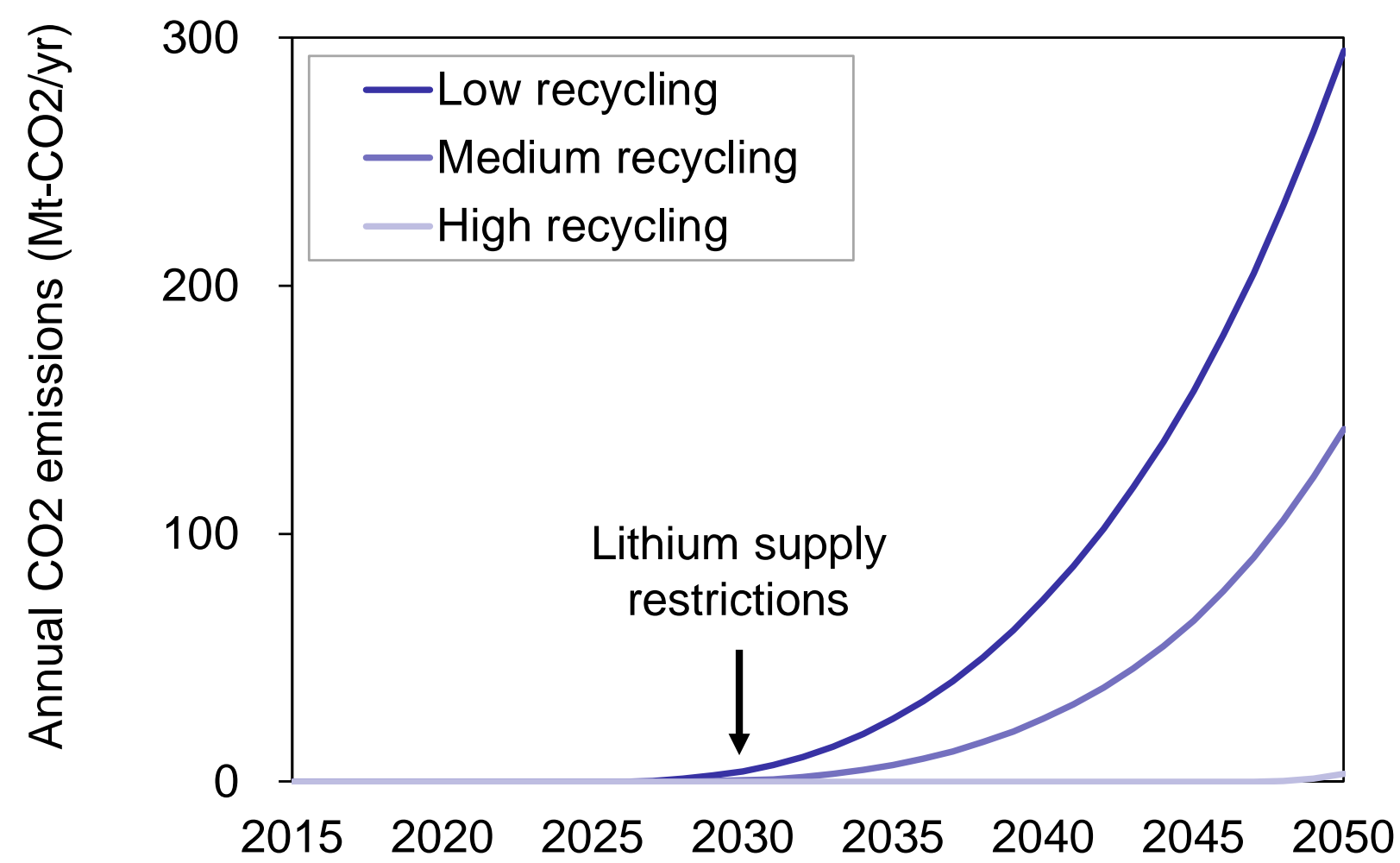

Figure 4. Increases in well-to-wheel $\mathrm{CO}_{2}$ emissions relative to the IEA's 2 Degree Scenario at the phase of vehicle operation in each scenario from 2015 to 2050 . Low,

Medium and High recycling scenarios assume $0 \%, 40 \%$ and $80 \%$ recycling rates, respectively. 


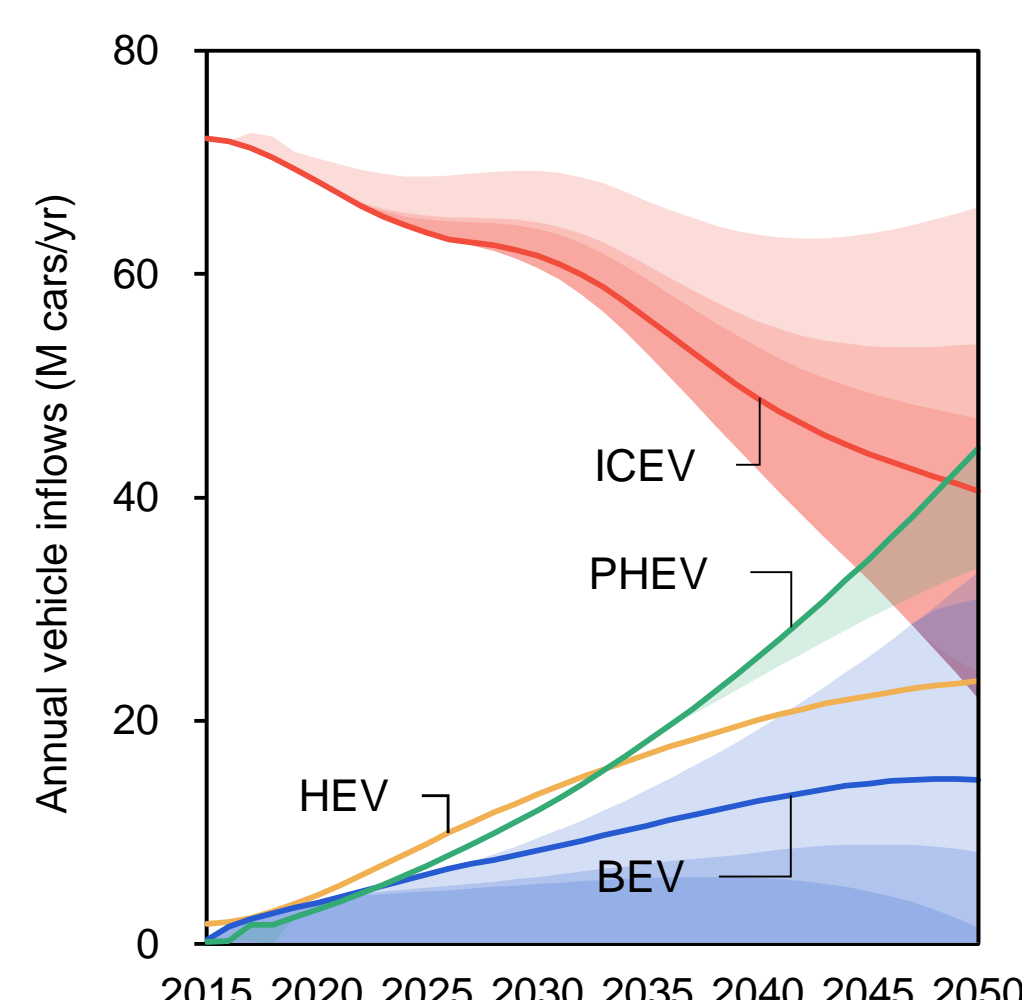

Ranges in 2050

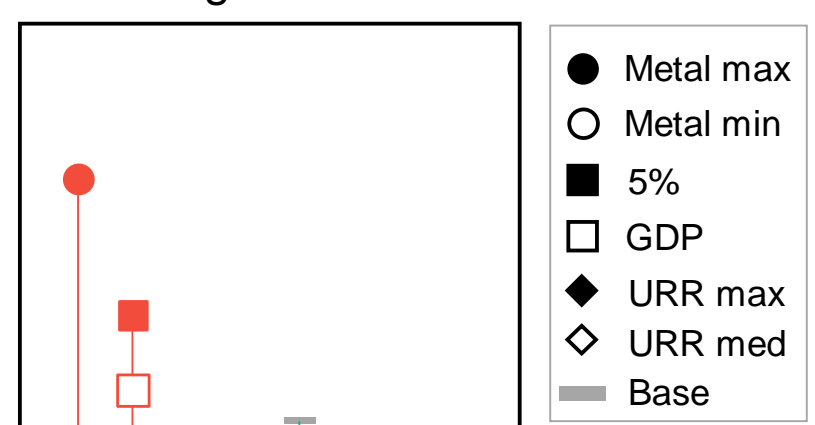

20152020202520302035204020452050

Figure 5. Sensitivity of the model to various assumptions indicating ultimately recoverable resources (URR), metal content, and growth rate for non-electric vehicle (non-EV) applications expressed by estimated inflows of each vehicle type to 2050. 'Base' reflects the representative value set in this study with a $0 \%$ recycling rate. 'Metal max' and 'Metal min' express respectively the maximum and minimum values in the lithium content of each vehicle type found in the literature $40,51,74-77$. 'GDP' and '5\%' indicate the growth rate for non-EV applications corresponding to the GDP growth rate in IEA's 2 Degree Scenario ${ }^{2}$ and $5 \%$ annual growth found in a previous study ${ }^{80}$. 'URR med' and 'URR max' demonstrate respectively the median and maximum values of estimated URR obtained from the literature ${ }^{71}$. Shaded areas represent ranges due to the assumptions and the bar on the right side indicates ranges of inflows for each vehicle type in 2050. 


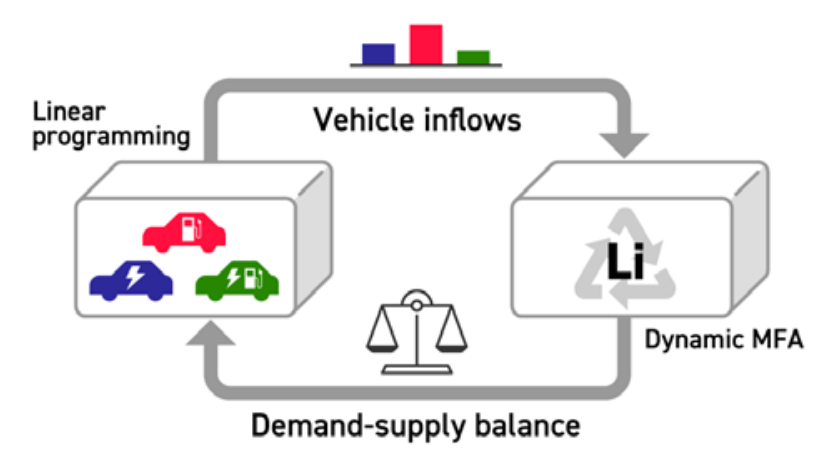

Graphical Abstract 